\title{
Ectopic pregnancy after right annessiectomy and left tubal ligation: case report
}

\author{
E. CASELLA, B. VENTURA, G. GIUNTA, M. CARIOLA, L. LO PRESTI, C. GALLO, \\ C.F. TOMASELLI, F. SAPIA, C. COMITO, L.M. CASTELLANO, G. DI SIMONE, S. CARUSO
}

SUMMARY: Ectopic pregnancy after right annessiectomy and left tubal ligation: case report.

E. Casella, B. Ventura, G. Giunta, M. Cariola, L. Lo Presti, C. Gallo, C.F. Tomaselli, F. Sapia, C. Comito, L.M. Castellano, G. Di Simone, S. Caruso

Objective. We report an unusual case of ectopic pregnancy in a woman with right annessiectomy and left tubal ligation.

Case report. A 35-year old woman underwent laparotomy right annessiectomy and left tubal ligations, because of a mature cystic teratoma attached to the right annex. She arrived in emergency three years later with lower abdominal pain, amenorrhea and a positive level of beta hCG (Beta subunit of human chorionic gonadotropin). An urgent videolaparoscopy was performed, with a left salpingectomy with the removal of the ectopic pregnancy in the distal remain tube. The pathologic report confirmed the diagnosis of ectopic pregnancy. The patient's postoperative recovery was normal.

Conclusion. The analysis of the literature/published data shows that the partial salpingectomy increases the risk of ectopic pregnancy, so total salpingectomy is the preferred option over partial salpingectomy, in order to reduce the risk of recurrent ectopic pregnancy.
RIASSUNTO: Gravidanza ectopica dopo annessiectomia destra e legatura tubarica sinistra: case report.

e. Casella, B. Ventura, G. Giunta, M. Cariola, L. Lo Presti, C. Gallo, C.F. Tomaselli, F. Sapia, C. Comito, L.M. Castellano, G. Di Simone, S. Caruso

Introduzione. Riportiamo il raro caso di una gravidanza extrauterina insorta in una donna precedentemente sottoposta ad annessiectomia destra e legatura della tuba sinistra.

Case report. Donna di 35 anni, sottoposta ad annessiectomia destra e legatura della tuba sinistra per via laparotomica per la presenza di un teratoma cistico maturo dell'annesso destro. Si presenta al Pronto Soccorso tre anni dopo riferendo algie pelviche ed amenorrea, ed esibendo dosaggi seriati di beta-hCG. La paziente viene sottoposta ad una laparoscopia in urgenza dove si esegue salpingectomia sinistra per gravidanza extrauterina insorta nel moncone distale. L'analisi istologica ha confermato la presenza di materiale trofoblastico che conferma la diagnosi di gravidanza ectopica. Il decorso post-operatorio è stato regolare.

Conclusioni. Dalla letteratura si evince che la salpingotomia aumenta il rischio di gravidanza ectopica, per cui è bene eseguire una totale salpingectomia nei casi di gravidanza extrauterina in modo da eliminare il rischio della ricomparsa di una gravidanza ectopica.

KEY WORDS: Ectopic pregnancy - Salpingectomy - Tubal ligation - Annessiectomy.

Gravidanza ectopica - Salpingectomia - Legatura tube - Annessiectomia.

\section{Introduction}

Miscarriage is the most common complication of early pregnancy and occurs in 15 to $20 \%$ of clinically evident pregnancies. Ectopic pregnancy is the implantation of a fertilized ovum outside of the en- dometrial cavity which occurs in approximately 1.5 to $2.0 \%$ of pregnancies, and it is a rare cause of spontaneous abortion. The $95 \%$ of ectopic pregnancies evolves in the oviduct $(1,2)$. The incidence of ectopic pregnancy increased by a factor of six between 1970 and 1992, but it has since remained stable. The

University of Catania, Catania, Italy

Department of Obstetrics and Gynaecology and Radiological Sciences

Section of Gynaecology and Obstetrics

(c) Copyright 2013, CIC Edizioni Internazionali, Roma 
associated mortality has decreased markedly to 0.5 deaths per 1000 pregnancies, mainly because of early diagnosis. Often the clinician or the patient did not recognize the early signs and symptoms of the ectopic pregnancy manifest with breakage (3).

Here, we report a rare case of a patient with an ectopic pregnancies after a right annessiectomy and left tubal ligation.

\section{Case report}

The patient P. A. 35 years old, gravida 3, para 2, presented herself to the emergency department of the Operative Unit of Gynecology and Obstetrics of the "Policlinico" of Catania, complaining of severe lower abdominal pain and amenorrhea for about $9^{+0}$ weeks.

She refers that in 2010 she underwent laparotomy right annessiectomy because of a cystic teratoma attached to the right annex and left tubal ligations to avoid pregnancy. She refers an ectopic pregnancies in the left tube the same year, which resolved without any therapy. In January 2013 she performed a laparoscopy surgery adhesiolysis.

The patient exhibits report of serum level of beta-hCG $1.983 \mathrm{mUI} / \mathrm{ml}$ at $6^{+4}$ weeks, $560 \mathrm{mUI} / \mathrm{ml}$ at 7 weeks and $529 \mathrm{mUI} / \mathrm{ml}$ at $7^{+4}$ weeks. The subsequent days, as a result of the above symptoms, the patient went to the obstetric emergency where she did a seriated blood test of beta-hCG (491,2 $\mathrm{mUI} / \mathrm{ml}$ at $7^{+5}$ weeks, $484,5 \mathrm{mUI} / \mathrm{ml}$ at 8 weeks and $375,7 \mathrm{mUI} / \mathrm{ml}$ at $8^{+4}$ weeks), complete blood counts (mild leukocytosis) and coagulation profile. In addition, the patient performs a clinical assessment by visit and transvaginal ultrasound. The ultrasound highlights at $8^{+4}$ weeks of amenorrhea in contiguity with the left ovary the presence of round echogenic, with a diameter of $25 \times 19 \mathrm{~mm}$ with no free fluid in the pouch of Douglas.

At $9^{+0}$ weeks of amenorrhea, she came back to the emergency department. The patient was alert, oriented in time and space, with blood pressure $103 / 57 \mathrm{mmHg}$. On examination, the abdomen was not manageable to deep palpation with pains in the left iliac fossa. An emergency blood test was taken for evaluate beta-hCG, the complete blood count and coagulation profile.

At the transvaginal ultrasound examination a shedding of $4 \mathrm{~cm}$ was present in the pouch of Douglas and a vascular mass with a diameter of $4 \times 4 \mathrm{~cm}$ laterally and left to the uterine, sore at the eco-palpation. The uterus was of regular shape and volume and the clinical picture was compatible with that of an ectopic pregnancy and hemoperitoneum.
After two hours, a second sampling was performed which showed a decrease in hemoglobin $(14.5 \mathrm{~g} / \mathrm{dl}$ to $12.2 \mathrm{~g} / \mathrm{dl}$ ) and hematocrit (from $43.3 \%$ to $37.3 \%$ ), with leukocytosis (increase of neutrophils and reduction of lymphocytes).

It was decided to refer the patient to an emergency laparoscopy.

The laparoscopic procedure has shown the presence of hemoperitoneum with free fluid in the pelvis, between the bowel loops and at the level of the dome right diaphragmatic. The right annex was absent for previous annessiectomy and the left ovary appeared regular. The left tuba had outcomes from previous tubal ligation such as scarring, but at the level of the ampulla in the distal stump appeared suddenly increased in size due to the presence of an ectopic pregnancy. Therefore salpingectomy is performed with removal of the ectopic pregnancy and repeated peritoneal drainage. During surgery, the blood loss was $500 \mathrm{cc}$ and transfusions was not necessary. The histological analysis revealed the presence of trophoblastic material that confirms the diagnosis of ectopic pregnancy.

In the second day after surgery the value of betahCG was reduced to $62.7 \mathrm{mIU} / \mathrm{ml}$ and the patient was discharged with gradual resumption of normal clinical conditions.

\section{Discussion}

Ectopic pregnancy remains an important cause of maternal death in the first trimester of pregnancy (4). The main risk factors of ectopic pregnancy include pelvic inflammatory disease, a significant infectious history, previous tuba surgery, previous ectopic pregnancy and the use of a intrauterine device. There are other risk factors such as smoking, age of more than 35 years and a high number of sexual partners. There is no correlation between ectopic pregnancy and previous use of oral contraceptives or induced abortion or spontaneous abortion and previous cesarean section. Conception is rare after tubal ligation, but if it occurs $25-50 \%$ of pregnancies are ectopic.

Even women with reduced fertility due to alterations in the tubal structure and/or tubal function, have an increased risk of ectopic pregnancy. Techniques of assisted reproduction increases the risk of ectopic pregnancy.

Half of the women is diagnosed ectopic pregnancy have no known risk factor (4-6).

In $50 \%$ of cases ectopic pregnancy manifests before breakage, with symptoms and signs compatible with the diagnosis of normally implanted pregnan- 
cy or spontaneous abortion. The symptoms and signs include:

- intermittent Metrorrhagia, like "spotting", light red or dark red, rarely more than a normal menstrual flow;

- abdominal pain such as cramp, unilateral or diffuse pelvic or abdominal-pelvic, mild to severe;

- amenorrhea.

Early diagnosis of tubal pregnancy can be made with transvaginal ultrasound and the measurement of the serum beta-hCG level.

If you are taking a single dose of serum beta$\mathrm{hCG}$ as an indirect index of gestational age it is necessary to define a discriminatory cut-off. The betahCG level corresponding to the ultrasound visualization of a normal intrauterine pregnancy with sensitivity close to $100 \%$. This cut-off is placed between the values of $1500-3000 \mathrm{mIU} / \mathrm{ml}$. The accuracy of the pelvic ultrasonography in the diagnosis of ectopic pregnancy increases, as the levels of betahCG increases: for levels below $1500 \mathrm{mIU} / \mathrm{ml}$, the positive predictive value for the diagnosis of intrauterine pregnancy is of only $80 \%$, while for the diagnosis of ectopic pregnancy is even $60 \%$.

Seriated measurements of beta-hCG may help in the differential diagnosis between pregnancies in evolution, a spontaneous abortion and ectopic pregnancy. In women with an ectopic pregnancy the levels of beta-hCG may to take different course: in $50 \%$ of cases it increases and in the remaining $50 \%$ it decreases. In $71 \%$ of ectopic pregnancies the increase of beta-hCG level is less than the level in the intrauterine pregnancies, and the decrease is slower than that observed in a spontaneous abortion (3).

The current management of ectopic pregnancy includes surgical or medical approach. The surgical intervention for tubal pregnancy can be radical (salpingectomy) or conservative (usually salpingostomy), both in laparoscopic approaches. The laparotomic approach is usually reserved for cases of breakage with intraperitoneal hemorrhage or shock. The medical option is the use of methotrexate, an antagonist of folic acid, administered intramuscularly according to protocols that provide a single dose or multiple doses. Studies show success rates of around 93\% for

\section{References}

1. Bouyer J, Coste J, Shojaei T, Pouly JL, Job-Spira N. Sites of ectopy pregnancy: a 10-year population-based study in France. Am J Epidemiol 2003;157:185-94.

2. LI-Ling C, Ming-Chao H. Recurrent ectopic pregnancy after ipsilateral segmental salpingectomy. Taiwan J Obstet Gynecol 2008;47:203-205. the multi-dose regimen and $88 \%$ for the single dose.

There are no randomized studies that indicate the optimal treatment - medical vs surgical - and no unanimous agreement on what levels of betahCG should be, where treatment with methotrexate is contraindicated.

Some ectopic pregnancies resolve spontaneously without treatment. If the woman decides to implement seriated controls without adopting any treatment, it is always extremely important to inform the woman that there is the risk of breakage of the ectopic pregnancy, even if the levels of beta-hCG are decreasing $(3,6,7)$.

\section{Conclusion}

In literature there are no identical cases of distal tubal ectopic pregnancies, but only rare cases of ectopic pregnancies in patients with previous salpingostomy, where the fertilized egg is implanted in the proximal stump of the tube. It is possible that this condition could result from either a contralateral fertilization that ascended the tubal stump or alternatively, an ovum having transmigrated and passed through a fistula into the tubal stump where successful sperm fertilization and implantation occurred $(2,6,8)$.

In our case, the only condition is that the fertilization and the implantation occurred in the distal residual tube.

Data in literature confirm that the partial salpingectomy increases the risk of ectopic pregnancy. In the cases of ectopic pregnancies, where it is not possible to preserve the fallopian tube with recanalization, a complete salpingectomy should be attempted in order to eliminate the risk of recurrent ectopic pregnancies and the associated morbidity and maternal death (6).

According to our experience we should have concern about all cases of amenorrhea in a fertile patient with a history of tubal sterilization, with the advice of always proceeding to the evaluation of serum beta-hCG and trans-vaginal ultrasound examination.
3. J Barnhart KT. Ectopic pregnancy. N Engl J Med 2009;361:379-87.

4. Dialani V, Levini D. Ectopic pregnancy: a review. Ultrasound 2004;20:105-17.

5. Farquhar CM. Ectopic pregnancy. Lancet 2005;366:583-91.

6. Yung-Liang L, Kwei-Shuai H, Po-Wei C, et al. Recurrent ectopic 
pregnancy in the ipsilateral ovidutto after prior laparoscopic partial salpingectomy. Taiwan J Obstet Gynecol 2009;48:417-419.

7. Skjeldestad FE, Hadgu A, Eriksson N. Epidemiology of repeat ectopic: a population-based prospective cohort study. Obstet
Gynecol 1998;91:129-35.

8. Szu-Yuan C, Ming-I H, Pui-ki C, et al. Recurrent ectopic pregnancy after partial salpingectomy. Taiwan J Obstet Gynecol 2009;48: 420-422. 